\title{
Método da eletrorresistividade aplicado no monitoramento temporal da pluma de contaminação em área de disposição de resíduos sólidos urbanos
}

\author{
Electrical resistivity method applied in the temporal monitoring of the \\ contamination plume in disposal area of urban solid waste
}

\author{
José Ricardo Melges Bortolin \\ Físico. Doutorando em Geociências e Meio Ambiente pelo Instituto de Geociências e Ciências Exatas da Universidade Estadual Paulista "Júlio de Mesquita \\ Filho" (Unesp), Campus Rio Claro (SP)
}

\author{
Walter Malagutti Filho \\ Geólogo. Livre-docente. Docente do Departamento de Geologia Aplicada do Instituto de Geociências e Ciências Exatas da Unesp, Campus Rio Claro (SP)
}

\begin{abstract}
Resumo
Este trabalho apresenta os resultados do monitoramento temporal da pluma de contaminação do aterro controlado de Rio Claro, São Paulo, por meio do método da eletrorresistividade, que consistiu na comparação dos resultados de várias seções de imageamento elétrico, executados nos mesmo locais, nos anos de 1999 e 2008. Zonas de baixa resistividade, com valores menores ou iguais a $50 \Omega$.m, foram associadas à contaminação por chorume. Desse modo, foi possível identificar dois sentidos do fluxo da pluma: (1) em direção ao sul, e (2) em direção ao oeste. Nas seções de 2008, a pluma de contaminação apresentou-se mais extensa e profunda do que em 1999. De forma complementar, as sondagens elétricas verticais aferiram a profundidade do nível freático e o sentido do fluxo d'água, subsidiando a interpretação dos imageamentos.
\end{abstract}

Palavras-chave: sondagem elétrica vertical; imageamento elétrico; aterro; chorume.

\begin{abstract}
This paper shows the results of a periodical monitoring of the contamination plume of a controlled landfill in Rio Claro, São Paulo, Brazil, using electrical resistivity geophysical method. The monitoring consisted on comparing the results of several electrical sections, performed at the same location, in the years of 1999 and 2008. Low resistivity zones, with values lower than or equal to $50 \Omega \mathrm{m}$, have been associated to contamination by leachate. Thus, it was possible to identify two directions for the contamination flows: (1) toward south, and (2) toward west. In the results of 2008, the contamination plume was more extensive and profound than in 1999. The vertical electrical soundings indicated the water table depth and the water flow directions, helping the interpretation of results of the electrical profiles.
\end{abstract} Keywords: vertical electrical sounding; electrical profile; landfill; leachate.

\section{Introdução}

A crescente produção mundial de resíduos sólidos urbanos gera diversos problemas, entre eles, o risco de contaminação de áreas de disposição (lixões, aterros controlados e sanitários) por chorume: um líquido contaminante, de cor escura, odor nauseante e de elevada demanda bioquímica de oxigênio (DBO), originado de processos biológicos, químicos e físicos da decomposição de resíduos orgânicos. Quando em contato com materiais geológicos, causa a diminuição da resistividade elétrica natural do material, devido à grande concentração de íons metálicos dissolvidos.
O risco de contaminação é significativamente maior quando esses locais não são devidamente preparados para tal finalidade. Exemplo disso são os lixões e aterros controlados, os quais representam 52,8\% dos locais de destinação de todo o lixo gerado no Brasil (IBGE, 2002). Uma vez que o meio natural é contaminado, sua recuperação tornase onerosa e, em muitos casos, impraticável. Daí a importância de estudos que possam identificar possíveis contaminações, em especial aqueles usando métodos geofísicos.

Uma das principais vantagens da aplicação dos métodos geofísicos em relação aos métodos tradicionais de investigação de subsuperfície (por exemplo, as sondagens e os poços de monitoramento) 
é a rapidez na avaliação de grandes áreas com custo relativamente menor (CETESB, 1999). Métodos geofísicos são eficientes na avaliação e caracterização de problemas ambientais; além disso, são de natureza não invasiva, o que significa que, a priori, não alteram o meio físico.

\section{Revisão bibliográfica}

$\mathrm{Na}$ literatura científica, pode-se encontrar inúmeros trabalhos relatando a utilização de métodos geofísicos em estudos de contaminação ambiental em áreas de disposição de resíduos, principalmente o método da eletrorresistividade (ER), aplicado com as técnicas do imageamento elétrico (IE) e/ou da sondagem elétrica vertical (SEV), por si só ou associado a outros métodos complementares.

Cavalcanti, Sato e Lima (2001) empregaram a técnica da SEV em estudos preliminares no Aterro Metropolitano Centro, em Salvador, Bahia. Por meio dos dados de resistividade elétrica, cargabilidade e potencial natural coletados, foi possível caracterizar e definir a localização do lençol freático e do topo rochoso, servindo como subsídio para a instalação de poços de monitoramento. Análises químicas realizadas em amostras de águas de poços e superficiais indicaram a não contaminação das mesmas, corroborando os resultados dos ensaios geofísicos.

Também Shiraiwa et al. (2002) realizaram estudos em um local semelhante, dessa vez no lixão desativado de Cuiabá, Mato Grosso. Analisando conjuntamente os dados levantados em campo por meio dos métodos da ER, eletromagnético (EM) e radar de penetração no solo (GPR), foi possível detectar contaminação por chorume desde a superfície até a profundidade da zona saturada, indicando a contaminação do lençol freático, assinalada por baixos valores de resistividade (> $20 \Omega$.m) associados a altos valores de condutividade $\left(<60 \mathrm{mS} . \mathrm{m}^{-1}\right)$.

Por meio dos métodos da ER e EM, ambos com a técnica do imageamento, Silva et al. (2002) verificaram a existência de contaminação no subsolo da área, atingindo inclusive o lençol freático, no lixão desativado de Ribeirão Preto, São Paulo. As linhas de IE executadas em cima das cavas de resíduos apresentam baixos valores de resistividade (> $20 \Omega . \mathrm{m})$ e altos valores de condutividade $\left(<40 \mathrm{mS} \cdot \mathrm{m}^{-1}\right)$, quando comparados com os resultados da linha de referência, executada a jusante da área do aterro. Pelo contexto da área, tais resultados indicam a contaminação por chorume.

Moura e Malagutti Filho (2003, 2007) utilizaram os métodos da ER e da polarização induzida (IP), aplicados com IE e SEV, para investigar a contaminação do lençol freático abaixo dos aterros controlados de Rio Claro e Piracicaba, São Paulo. Por ambas as técnicas, detectou-se zonas de baixa resistividade elétrica, resultado da contaminação das áreas por chorume. Análises químicas de amostras de água coletadas em poços cacimba e de monitoramento indicaram elevadas concentrações de íons cloreto $\left(\mathrm{Cl}^{-}\right)$, sódio $\left(\mathrm{Na}^{+}\right)$, sulfatos $\left(\mathrm{SO}_{4}^{-2}\right)$ e nitrato $\left(\mathrm{NO}_{3}^{-2}\right)$.

Lago, Elis e Giacheti (2006) também utilizaram as técnicas de IE e SEV, combinando os métodos de ER, IP e potencial espontâneo (SP), para investigar a existência de contaminação no subsolo do aterro de Bauru, São Paulo. Os métodos da ER e da IP permitiram diferenciar as cavas com resíduos $(<20 \Omega$.m) dos materiais natu-

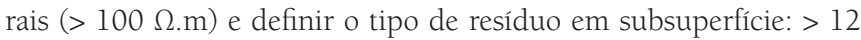
$\mathrm{mV} . \mathrm{V}^{-1}$ para materiais polarizáveis e $<4 \mathrm{mV} \mathrm{V}^{-1}$ para água subterrânea com sais dissolvidos e chorume. O método do SP permitiu, principalmente, mapear o fluxo subterrâneo. O resultado dessa integração de métodos auxiliou na locação de poços de monitoramento e detectou a posição de prováveis contaminações, direcionando a realização de ensaios diretos comprobatórios (análises químicas de amostras de água), os quais indicaram contaminação por cádmio, cromo total e níquel, além de alteração nos valores de DBO e DQO (demanda química de oxigênio).

Fachin et al. (2006) desenvolveram um trabalho semelhante, empregando os métodos de ER, EM e GPR, em uma área de disposição de resíduos industriais de um curtume, na cidade de Várzea Grande, Mato Grosso. Ali eram dispostos pêlos, gorduras, restos de carne e lodo de tratamento biológico, contendo água, sais de cromo, zircônio, alumínio, ferro, curtentes vegetais, sintéticos, aldeídos e parafinas sulfocloradas. Os baixos valores de resistividade

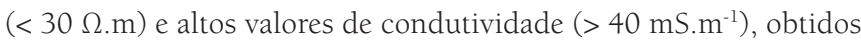
nas linhas executadas em cima de locais onde eram dispostos os resíduos, indicaram a presença de contaminantes em subsuperfície. Já os valores obtidos na linha de referência, onde não existe contaminação, são significativamente diferenciados: resistividade acima de $50 \Omega$.m e condutividade menor que $20 \mathrm{mS} . \mathrm{m}^{-1}$. Os três métodos utilizados são complementares, cada qual corroborando o resultado dos outros.

Determinar a existência de contaminantes em subsuperfície é importante, porém, não é suficiente. Também é desejável que se faça um acompanhamento da situação monitorando-se temporalmente o local por meio da repetição dos ensaios, a fim de se compararem os resultados ao longo do tempo. Desse modo, é possível compreender plenamente o comportamento do contaminante, além de permitir um melhor planejamento para a remediação do problema (BORTOLIN, 2009).

Entretanto, verifica-se a escassez de obras abordando não somente a determinação e extensão da contaminação ambiental, mas também o monitoramento dessa contaminação no decorrer do tempo. São exemplos os trabalhos de Moreira e Dourado (2007), Moreira, Aquino e Dourado (2007) e Moreira e Braga (2009a), os quais reportam a utilização dos métodos EM, GPR, ER e IP para estudar a evolução da pluma de contaminação em uma área localizada no distrito industrial do município de Araras, São Paulo, 
onde eram fabricados dieloxalato, acetato de etila, 4-amino-N-2tiozolil-benzeno-sulfonamida, acetopiruvato de metila, 5-metil-3carboxiamidoxazol (carboxamido), e utilizados 1,2 dicloroetano e tolueno como solventes.

Mais escassos ainda são os trabalhos de pesquisa que utilizam o método da ER no monitoramento temporal de áreas de disposição de resíduos sólidos. No que tange a esse assunto, somente duas obras nacionais são conhecidas até o presente momento: Moreira (2009) e Moreira e Braga (2009b). Ambos relatam a utilização dos métodos de ER, IP e SP para se determinar a evolução da pluma de contaminação no aterro controlado do município de Cordeirópolis, São Paulo. Os dados foram obtidos sobre valas anualmente fechadas entre dezembro de 2001 e dezembro de 2007 (MOREIRA, 2009).

Os resultados indicam que os valores dos parâmetros investigados estão diretamente relacionados ao tempo de permanência dos resíduos nas valas. Os maiores valores de cargabilidade (método IP) foram detectados em valas recém fechadas, diminuindo gradativamente em direção às valas mais antigas.

No método do SP, os maiores valores (positivos) estão associados às valas mais antigas, enquanto que na vala referente ao ano de 2007 , os valores são próximos a zero. Menos pronunciada, mas evidente é a variação dos valores de resistividade elétrica de acordo com o tempo de fechamento das valas. Valas fechadas no início da operação do aterro (2001) apresentam valores de resistividade relativamente maiores do que aqueles verificados em valas fechadas mais recente-

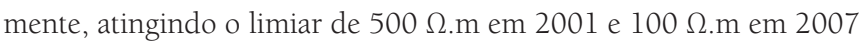
(MOREIRA, 2009).

Assim, diante do contexto apresentado, desenvolveu-se um trabalho de monitoramento temporal da pluma de contaminação do aterro controlado desativado do município de Rio Claro, por meio da comparação dos resultados obtidos utilizando-se o método da ER nos anos de 1999 (MOURA, 2002) e 2008 (BORTOLIN, 2009).

\section{Metodologia}

\section{Localização e descrição da área}

O aterro controlado de Rio Claro localiza-se ao sul do município, na altura do kilômetro 3, às margens da rodovia Fausto Santomauro (SP 127), a qual liga o município a Piracicaba, na faixa de sentido Rio Claro-Piracicaba, e possui uma área de 44.242,16 m² (TANDEL, 1998) (Figura 1).

Esse local teve origem no ano de 1982, como um lixão instalado numa antiga voçoroca, e foi concebido para receber resíduos de origem dos serviços de limpeza pública do município. Entre 1988 e 1992, o gerenciamento do local ficou a cargo da empresa SPA (Sistemas de Proteção Ambiental Ltda.), a qual realizou a instalação de drenos para a coleta de gases e de percolado, transformando o antigo lixão em aterro controlado.

Os drenos foram construídos com brita de basalto $n^{\circ} 4$. O percolado era conduzido por canaletas de concreto até um poço concretado do sistema de recirculação, sendo que a quantidade gerada era de, no máximo, 42 L por hora na época das chuvas, chegando a zero na seca. Os gases eram eliminados nos queimadores, mantidos constantemente acesos. A base do aterro não recebeu nenhum tipo de impermeabilização. Ensaios de laboratório apontam valores do coeficiente de permeabilidade da base do aterro nunca superiores a $10^{-6}$ cm.s.-1 (TANDEL, 1998).

Os resíduos coletados eram dispostos diretamente no aterro, sem separação ou tratamento intermediário, em células de $4 \mathrm{~m}$ de altura, em média. Eram recobertos com uma camada de material de cobertura com cerca de $0,5 \mathrm{~m}$ e compactado por trator de esteira. A densidade final de compactação girava em torno de $600 \mathrm{~kg} \cdot \mathrm{m}^{-3}$ (BRAZ; SILVA, 2001).

As atividades no aterro foram encerradas em setembro de 1997 e, em caráter emergencial, utilizou-se uma área contígua, a leste do aterro. Após o término das operações de disposição de resíduos, todo o aterro foi coberto com uma camada de solo de, aproximadamente, 0,5 m

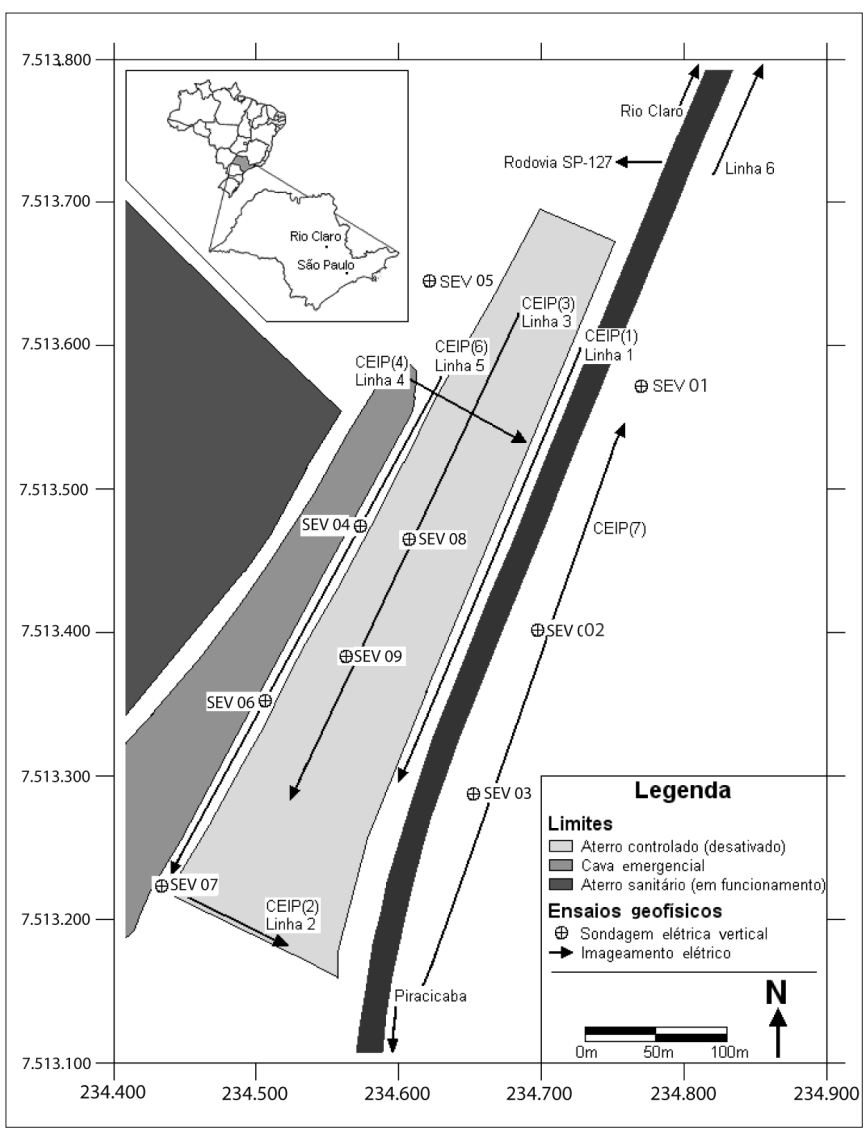

Figura 1 - Localização da área, indicando a posição dos ensaios geofísicos - modificado de Base Aerofotogrametria e Projetos S.A. (2006). 
No entorno do aterro, verifica-se o domínio de lavouras de canade-açúcar, destinadas a atender a agroindústria do açúcar e do álcool.

\section{Geologia}

De acordo com Cottas (1983) e Zaine (1994), as unidades litoestratigráficas que afloram na região do aterro são: (1) Formação Corumbataí: constituída localmente principalmente por siltitos. Sua espessura na região de Rio Claro não ultrapassa os 130 m; (2) Formação Rio Claro: assentada discordantemente sobre a Formação Corumbataí. Apresenta espesso solo arenoso (8 a $12 \mathrm{~m}$ ), arenitos com variações de granulometria e intercalações de camadas de conglomerados e lentes argilosas. Possui espessura média entre 25 e 30 m e máxima de $40 \mathrm{~m}$.

\section{Método da eletrorresistividade}

O método da ER fundamenta-se no fato de que diferentes materiais, geológicos ou não, apresentam diferentes valores de resistividade elétrica. A resistividade elétrica ( $\rho$ ) é um parâmetro intrínseco dos materiais, o qual se relaciona à dificuldade encontrada por uma corrente elétrica para se propagar em um meio e depende, entre outras coisas, da natureza e do estado físico do corpo considerado.

Nesse método, uma corrente elétrica (I) é injetada no solo através de um par de eletrodos metálicos, e a diferença de potencial $(\Delta V)$ relacionada a essa corrente é medida por meio de um segundo par de

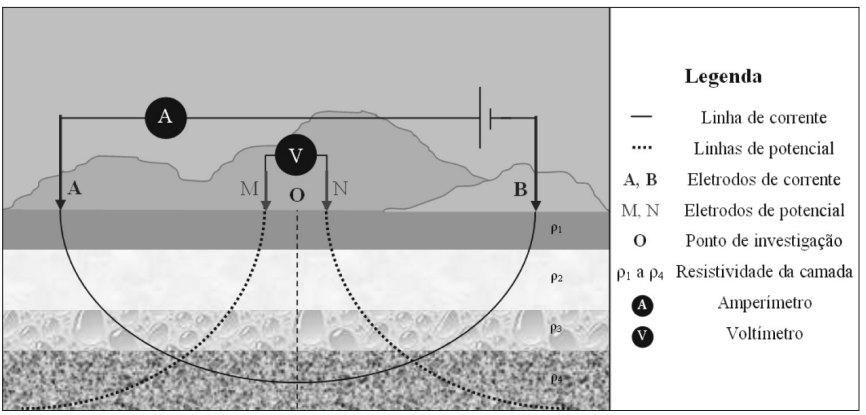

Figura 2 - Técnica da sondagem elétrica vertical com arranjo Schlumberger (BORTOLIN, 2009)

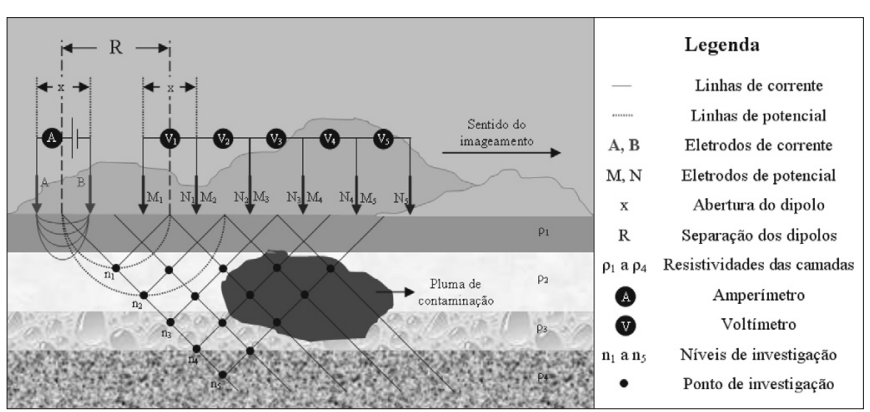

Figura 3 - Técnica do Imageamento Elétrico com arranjo Dipolo-Dipolo (BORTOLIN, 2009) eletrodos. Aplicando-se a Lei de Ohm e levando-se em conta um fator de espaçamento entre os eletrodos $(K)$, a resistividade aparente $\left(\rho_{\mathrm{a}}\right)$ de um meio geológico, conforme Zonge, Wynn e Urquharts (2005), pode ser calculada por meio da Equação 1:

$\rho_{a}=\frac{\Delta V}{I} K$

Equação 1

A base do monitoramento temporal aqui empregado reside na repetição de ensaios geofísicos, nos mesmos locais e utilizando-se as mesmas técnicas determinadas por Moura (2002) - principal referência bibliográfica adotada - e na comparação dos resultados obtidos nos diferentes anos. Desse modo, optou-se pelas técnicas da SEV e do IE, respectivamente com arranjos Schlumberger e Dipolo-Dipolo, a fim de reproduzir as mesmas condições anteriores.

\section{Sondagem elétrica vertical}

Consiste na investigação da variação de um parâmetro físico no caso, a resistividade elétrica - em profundidade, a partir de medidas efetuadas na superfície do terreno. O arranjo utilizado foi o Schlumberger, conforme a Figura 2.

Nesse arranjo, a distância entre os eletrodos de corrente A e B deve ser cinco vezes maior ou igual à distância entre os eletrodos de potencial M e N, conforme a Equação 2:

$M N \leq \frac{A B}{5}$

Equação 2

A aquisição dos dados foi feita utilizando-se um resistivímetro BISON 2390. O máximo espaçamento AB/2 empregado foi de 100 $\mathrm{m}$ nas SEV dentro do aterro e de $150 \mathrm{~m}$ nas SEV fora do aterro, totalizando 9 ensaios. Os dados foram processados no software Interpex IX1D, versão 2.17, da Interpex Limited (2008).

As SEV foram distribuídas de modo a estabelecer uma malha otimizada, de espaçamento aproximadamente regular, sem a preocupação demasiada de coincidi-las com os ensaios anteriores (MOURA, 2002), pois serviram de base para a interpretação dos resultados dos IE e para a elaboração do mapa potenciométrico da área.

\section{Imageamento elétrico}

O IE consiste na obtenção de valores de um parâmetro físico novamente, a resistividade elétrica - a partir da superfície terrestre e ao longo de uma seção, e na interpretação da sua variação horizontal a uma ou mais profundidades determinadas. $\mathrm{O}$ arranjo utilizado foi o dipolo-dipolo com cinco níveis de investigação (Figura 3).

Foram executadas 6 linhas de IE, com extensões que variaram entre 90 e 420 m. A aquisição dos dados no ano de 1999 foi feita utilizandose um resistivímetro SCINTREX IPR-12 e, em 2008, um resistivímetro ABEM TERRAMETER SAS 4000 e um resistivímetro BISON 2390. 
Os dados dos IE executados em 1999 e em 2008 foram processados com o software Res2dinv v.3.4, da Geotomo Software (2002), utilizando-se o mesmo tipo de processamento para todas as seções, as quais foram comparadas qualitativa e quantitativamente entre si, possibilitando traçar uma linha evolutiva da pluma de contaminação presente na área.

\section{Resultados e discussões}

\section{Sondagens elétricas verticais}

Mediante a interpretação das curvas de campo das SEV, assumiuse que a base do aterro encontra-se na Formação Rio Claro, devido aos valores de resistividade elétrica obtidos situarem-se na faixa de

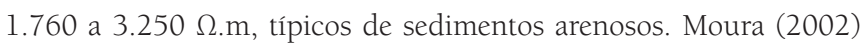
também interpretou que os sedimentos da base do aterro pertencem à Formação Rio Claro, com base em descrições de sondagens à percussão.

Por meio das SEV 01, 02 e 03, foi possível detectar uma camada de sedimentos argilosos, ocorrendo entre as cotas 560 e $578 \mathrm{~m}$, e intercalada aos sedimentos arenosos da Formação Rio Claro. É provável que essa camada argilosa apresente continuidade lateral, em direção à cava de resíduos, atuando como impermeabilizante natural da base do aterro, que se encontra, aproximadamente, entre as cotas 566 e 574 m. Entretanto, de acordo com Braga (2001), a resistividade elétrica de sedimentos argilosos saturados é igual ou inferior a 20

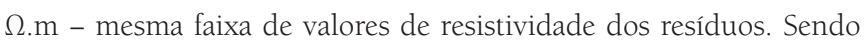

assim, não foi possível diferenciar geoeletricamente a camada argilosa dos resíduos.

Ainda por meio da interpretação das SEV, foi possível gerar o mapa potenciométrico da área de estudos e identificar que o nível freático, no período da estiagem, está situado entre 9,10 e 14,80 m e tem sentido de fluxo para Sudeste (SE).

\section{Monitoramento temporal (imageamentos elétricos)}

Diferentemente dos trabalhos de Moreira (2009) e de Moreira e Braga (2009b), que executaram o monitoramento em uma área controlada de disposição de resíduos sólidos, para análise do comportamento temporal dos materiais enterrados e verificação da hipótese de aplicação e uso dos métodos geofísicos em estudos que prevejam o término da geração de chorume em aterros, o enfoque dado a este trabalho foi a utilização do método da ER para acompanhar a evolução temporal da pluma de contaminação, inferindo-se suas dimensões e valores de resistividade.

O monitoramento temporal da pluma de contaminação na área do aterro controlado foi executado por meio da comparação das seções de resistividade resultantes dos IE de 1999 e de 2008. Como explicitado na Figura 1, foram executados seis ensaios do tipo IE. Entretanto, somente os mais expressivos são apresentados aqui. Para maiores informações, consultar Bortolin (2009).

Por meio dos ensaios CEIP(7) e Linha 6 (Figura 4), adotados como referências em 1999 e 2008, respectivamente, foi possível delimitar o background da área, onde valores iguais ou maiores a 140

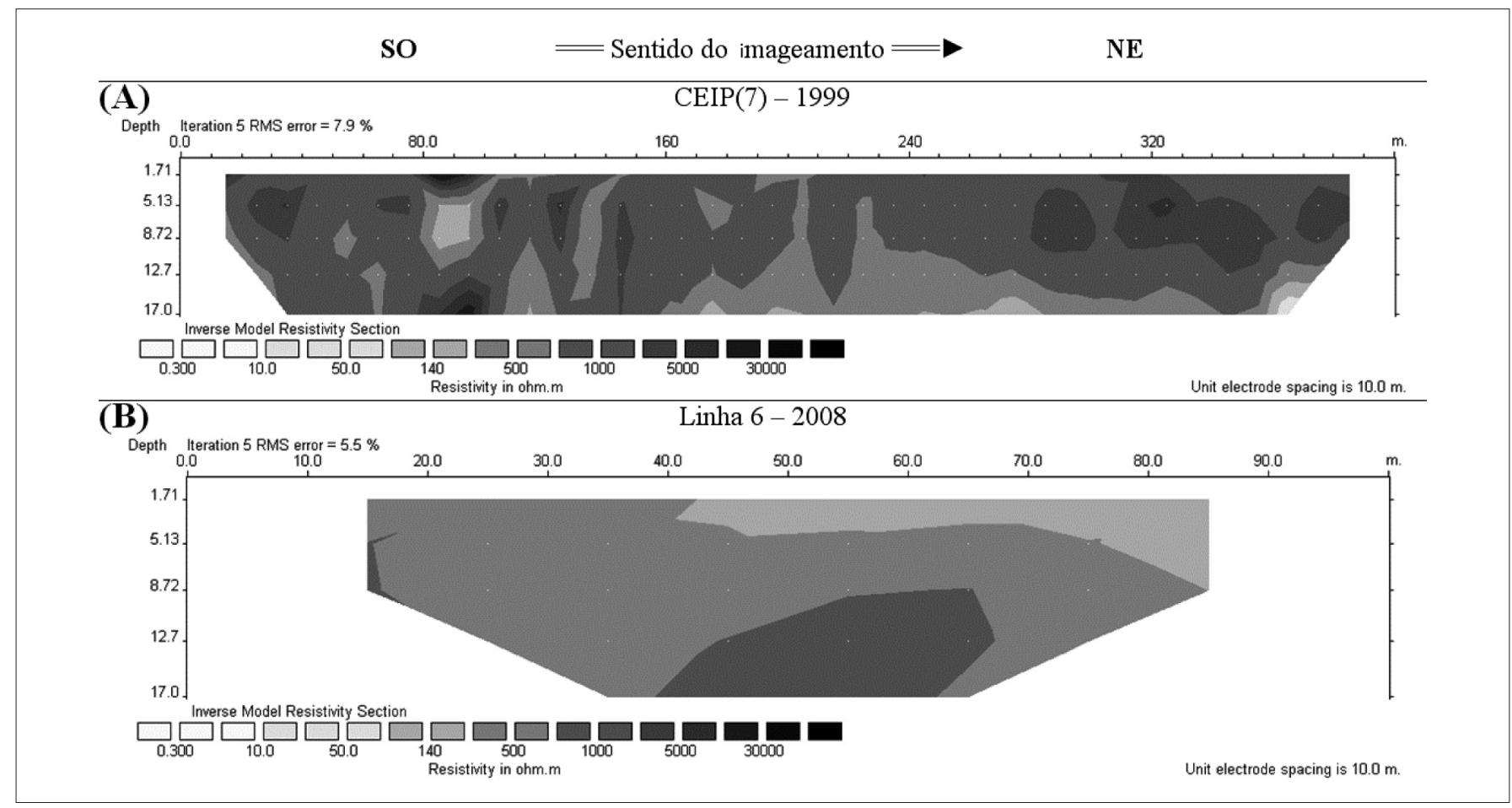

Figura 4 - (A) Seção de resistividade aparente do ensaio CEIP(7); (B) seção de resistividade aparente do ensaio Linha 6 
$\Omega$.m indicam ambiente natural isento de contaminação por chorume. Desse modo, definiu-se que valores abaixo de $140 \Omega$.m indicam provável contaminação por chorume.

O ensaio $\operatorname{CEIP(2)}$ foi executado paralelamente ao limite sul do aterro, no sentido de seu eixo menor (Figura 1). No ano em que foi executado (1999), o aterro encontrava-se em operação e a disposição dos resíduos no local era feita no sentido aproximado Norte-Sul. Portanto, a região onde foi realizado o referido ensaio foi a última a receber os resíduos, justificando os elevados valores de resistividade aparente aí encontrados (Figura 5A). Essa seção apresenta-se majoritariamente resistiva, com valores maiores ou iguais a $140 \Omega$.m, isentando quase por completo a possibilidade de haver contaminação do subsolo nesse local. Pequenas zonas de baixa resistividade ( $\geq 50$ $\Omega . \mathrm{m})$ em profundidades maiores do que $6 \mathrm{~m}$, nesse contexto, podem indicar o nível freático.

A Linha 2 (Figura 5B), executada no ano de 2008, foi realizada no mesmo local do ensaio CEIP(2). Apesar de os valores máximos e mínimos das duas seções serem idênticos, a distribuição desses valores em cada seção é totalmente diferente. Com esse ensaio, foi possível delimitar a cava de resíduos, entre as estacas de 35 e $40 \mathrm{~m}$ da seção. À esquerda desse ponto, ocorrem resistividades acima de $140 \Omega$.m, refletindo os sedimentos predominantemente arenosos da Formação Rio Claro isentos de contaminação. À direita da estaca de $40 \mathrm{~m}$ tem-se uma grande zona de baixa resistividade $\left(\rho_{\mathrm{a}} \leq 50 \Omega \mathrm{m}\right)$, relativamente ao restante da seção, associada à presença de resíduos e com o provável sentido de migração da pluma de contaminação: esse é o fluxo principal, em direção ao sul do aterro.

O ensaio CEIP(6) de 1999 (Figura 6A) foi realizado em uma estrada não pavimentada, externa ao aterro controlado e vizinha a ele (Figura 1). Essa estrada encontra-se sobre um divisor de águas, com quedas nas direções Sudeste e Noroeste, aproximadamente. A zona de baixa resistividade $\left(\rho_{\mathrm{a}} \leq 50 \Omega\right.$.m) é atribuída ao fluxo de contaminantes proveniente da cava emergencial; encontra-se localizada a partir da estaca de $155 \mathrm{~m}$ e em profundidades maiores no extremo direito da seção (estaca de $270 \mathrm{~m}$ ), pois a produção e o fluxo de chorume são mais antigos nessa região, fazendo com que a pluma de contaminação atingisse profundidades maiores nesse local em comparação ao restante da seção. A região situada entre as estacas de 0 e $140 \mathrm{~m}$, (Figura 6A), apresenta valores de resistividade aparente maiores ou iguais a $140 \Omega$.m, típicos de ambiente isento de contaminação, justificados pela inexistência de resíduos na cava emergencial nesse trecho do ensaio.

A Linha 5 (Figura 6B) foi executada no mesmo local do ensaio CEIP(6). É facilmente notável que essa seção exibe uma camada superficial, com aproximadamente $5 \mathrm{~m}$ de espessura e valores de resistividade maiores ou iguais a $140 \Omega$.m, a qual pode ser interpretada como sedimentos predominantemente arenosos e material de empréstimo para cobertura dos resíduos. Tais valores também são encontrados nos flancos esquerdo e, principalmente, direito da seção, sendo que este pode ser associado com o limite sul da cava emergencial.

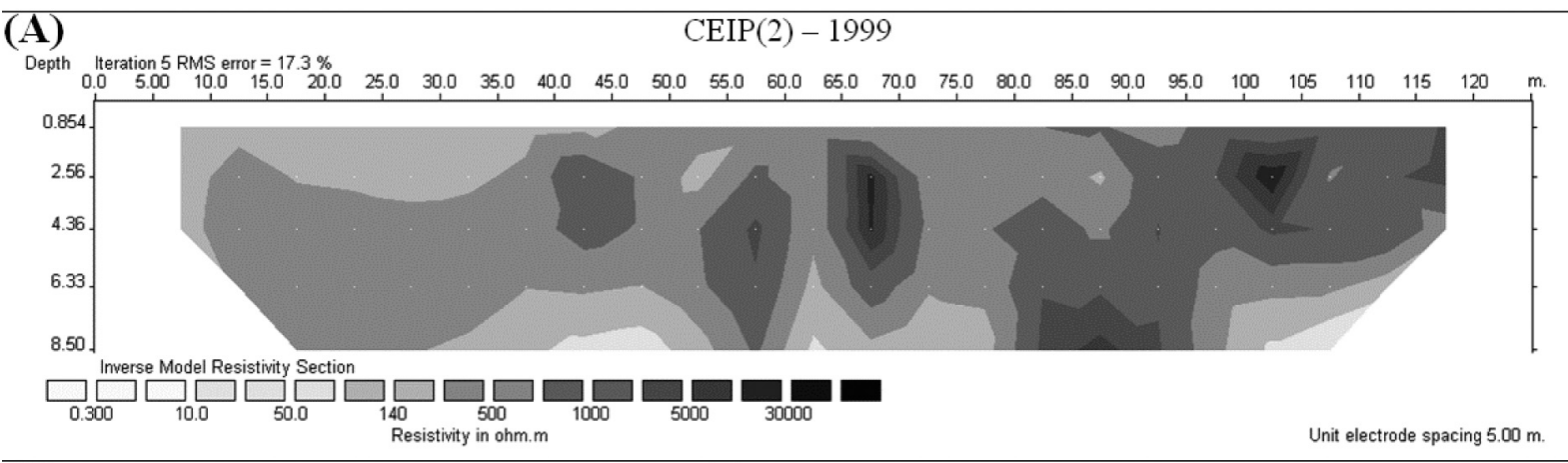

(B)

Linha 2-2008

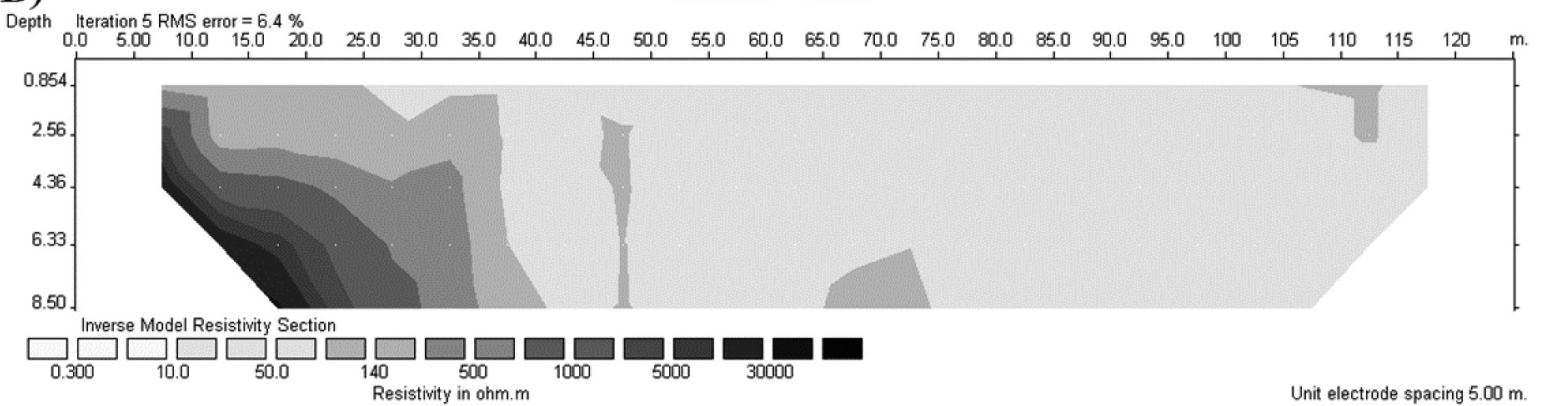

Figura 5 - (A) Seção de resistividade aparente do ensaio CEIP(2); (B) seção de resistividade aparente do ensaio Linha 2 
A grande região com resistividades entre 0,3 e $50 \Omega$.m, que se encontra a profundidades maiores do que $5 \mathrm{~m}$ e estende-se por quase toda a seção, pode ser associada com materiais geológicos em subsuperfície contaminados por chorume proveniente do aterro controlado e da cava emergencial, já que, na data de realização do ensaio, havia resíduos depositados por toda a extensão de ambas as áreas.

Como pôde ser verificado em campo, no topo do aterro controlado existem duas "lagoas" do sistema de recirculação de chorume que ainda recebem volumes consideráveis de chorume, originário do novo aterro (sanitário) (Figura 1). É provável que parte do contaminante tenha migrado das "lagoas" em direção ao subsolo do local do ensaio. Essa hipótese explicaria a zona de muito baixa resistividade ( $\rho a \leq 10 \Omega . m$ ), encontrada na região central da seção e que coincide com a localização das duas "lagoas" de chorume no aterro controlado. Esse fluxo de contaminante, dirigindo-se ao oeste da área, foi denominado fluxo secundário.

\section{Conclusões}

A cava de resíduos do aterro controlado de Rio Claro está inserida em uma porção de material predominantemente arenoso, com intercalações de argila pertencentes à Formação Rio Claro. Esta se encontra assentada discordantemente sobre a Formação Corumbataí, constituída localmente por siltitos, a qual atua como impermeabilizante natural, impedindo o fluxo vertical da pluma de contaminação a profundidades maiores.

Foram identificados dois fluxos predominantes da pluma de contaminação, sendo o principal na direção sul e o secundário na direção oeste. O fluxo principal aparenta ser governado pelo fluxo d'água subterrâneo, que tem sentido para sudeste. O nível freático, no período da estiagem, situa-se entre 9,10 e 14,80 m de profundidade.

$\mathrm{O}$ procedimento de monitoramento temporal adotado permitiu verificar alterações dos valores de resistividade e, principalmente, das dimensões da pluma de contaminação. Relativamente aos resultados de Moura (2002), a pluma mostrou-se maior e mais profunda em 2008, contrariando o que se esperava para um aterro desativado há pelo menos, dez anos.

O aumento das dimensões da pluma pôde ter recebido significativa contribuição das "lagoas" do sistema de recirculação de chorume, mantidas quase que constantemente cheias.

Por fim, deve-se ressaltar que somente os resultados dos ensaios geofísicos não são suficientes para se afirmar a existência de contaminação do solo e da água subterrânea, seja na região do referido aterro ou em qualquer outro local a ser estudado, já que estes apenas fornecem indícios da existência de contaminantes. A contaminação e os níveis de contaminantes somente podem ser confirmados por meio de análises físico-químicas de amostras de solo e água, obtidas por meio de sondagens e poços de monitoramento.

\section{Agradecimentos}

Ao Conselho Nacional de Desenvolvimento Científico e Tecnológico (CNPq), financiador desta pesquisa, ao técnico Francisco Manuel Garcia Barrera e a todos os amigos que colaboraram nos trabalhos de campo: José, Luís, Amanda, Robson, Demétrio, César, Fabrício, Sueli e Daniel.

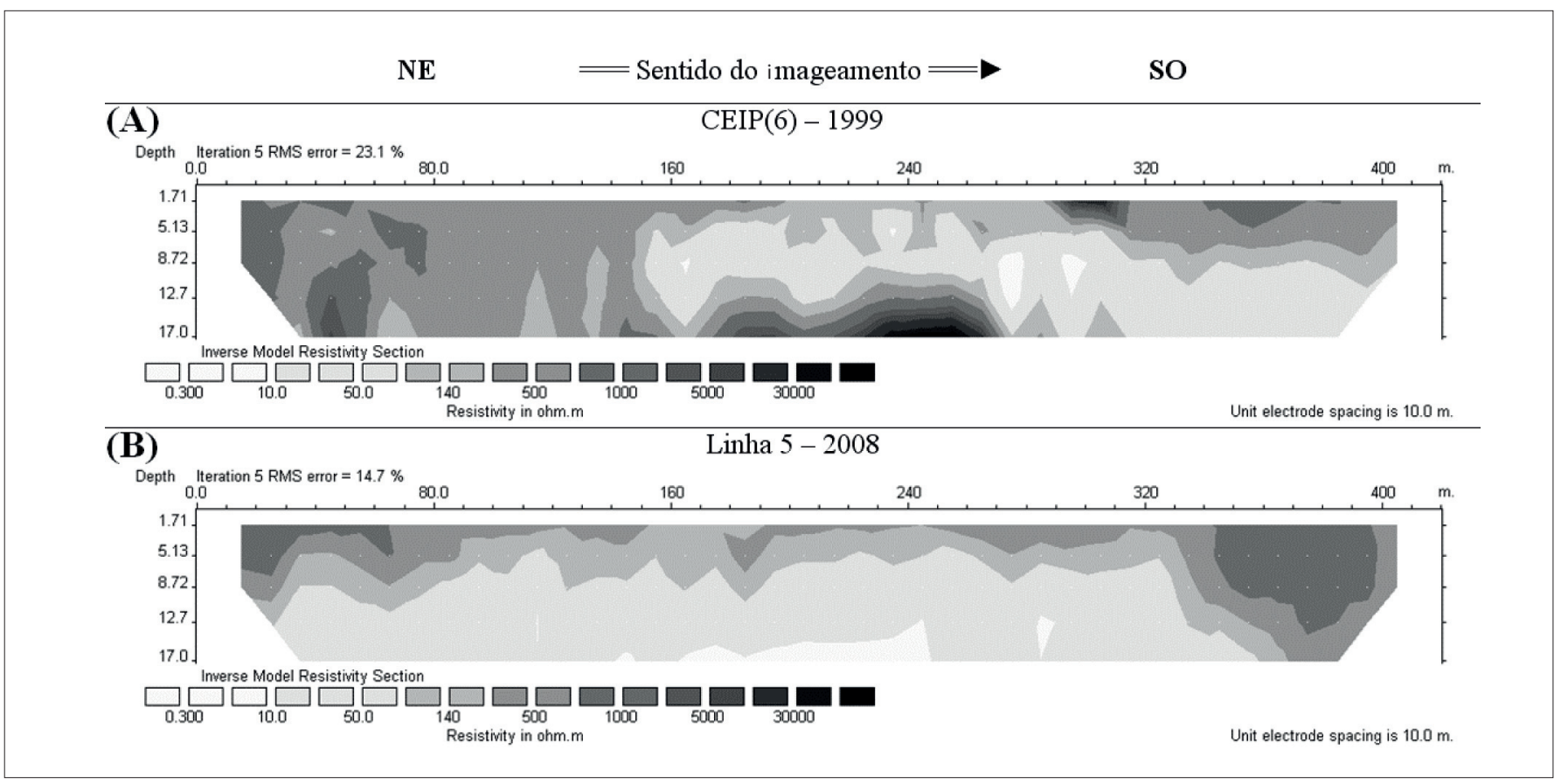

Figura 6 - (A) Seção de resistividade aparente do ensaio CEIP(6); (B) seção de resistividade aparente do ensaio Linha 5 


\section{Referências}

BASE AEROFOTOGRAMETRIA E PROJETOS S.A. Rio Claro. São Paulo, 2006. 1 fotografia aérea. Escala 1:30.000.

BRAGA, A.C.O. Métodos geoelétricos aplicados: Módulo: Hidrogeologia. 2001. Disponível em: <http://www.rc.unesp.br/igce/aplicada/ geoeletricos-V3.pdf>. Acesso em: 12 nov. 2007.

INSTITUTO BRASILEIRO DE GEOGRAFIA E ESTATÍSTICA (IBGE). Pesquisa nacional de saneamento básico - 2000. 2002. Disponível em: $<$ http://www.ibge.gov.br/home/estatistica/populacao/condicaodevida/ pnsb/pnsb.pdf >. Acesso em: 27 nov. 2008.

BRAZ, J.A.; SILVA, C.L. Avaliação do potencial energético do biogás de aterro sanitário gerado pelos resíduos sólidos domésticos do município de Rio Claro. In: CONGRESSO BRASILEIRO DE ENGENHARIA SANITÁRIA E AMBIENTAL, 21, 2001, João Pessoa. Anais... Florianópolis: 2001. Paginação irregular.

BORTOLIN, J.R.M. Monitoramento temporal da pluma de contaminação do aterro controlado de Rio Claro (SP) por meio do método da eletrorresistividade. Dissertação (Mestrado em Geociências e Meio Ambiente), Universidade Estadual Paulista "Júlio de Mesquita Filho", Rio Claro, SP, 2009.

CAVALCANTI, S.S.; SATO, H.K.; LIMA, O.A.L. Geofísica elétrica na caracterização da hidrologia subterrânea na região do Aterro Metropolitano Centro, Salvador, Bahia. Revista Brasileira de Geofísica, v. 19, n. 2, p. 155-168, 2001

COMPANHIA AMBIENTAL DO ESTADO DE SÃO PAULO (CETESB). Manual de gerenciamento de áreas contaminadas: Métodos geofísicos. 1999. Disponível em: <http://www.cetesb.sp.gov.br/Solo/areas_ contaminadas/manual.asp >. Acesso em: 6 dez. 2006.

COTTAS, L.R. Estudos geológico-geotécnicos aplicados ao planejamento urbano de Rio Claro - SP. 1983. Tese (Doutorado em Geologia), Universidade de São Paulo, São Paulo, SP, 1983.

FACHIN, S.J.S. et al. Aplicação de métodos geofísicos para identificar áreas contaminadas por resíduos de um curtume. Revista Brasileira de Geofísica, v. 24, n. 1, p. 129-138, 2006.

GEOTOMO SOFTWARE. RES2DINV ver. 3.4: $2 \mathrm{D}$ Resistivity and IP Inversion. Penang, Malaysia: Geotomo Software, 2002

INTERPEX LIMITED. IX1D v. 2.17. Golden, Co, USA: Interpex Limited, 2008.

LAGO, A.L.; ELIS, V.R.; GIACHETI, H.L. Aplicação integrada de métodos geofísicos em uma área de disposição de resíduos sólidos urbanos em Bauru-SP. Revista Brasileira de Geofísica, v. 24, n. 3, p. 357-374, 2006

MOREIRA, C.A. Geofísica aplicada no monitoramento de área de disposição de resíduos sólidos domiciliares. Tese (Doutorado em
Geociências e Meio Ambiente), Universidade Estadual Paulista "Júlio de Mesquita Filho", São Paulo, SP, 2009.

MOREIRA, C.A.; AQUINO, W.F.; DOURADO, J.C. Aplicação do método eletromagnético indutivo (EM) no monitoramento de contaminantes em subsuperfície. Revista Brasileira de Geofísica, v. 25. n. 4. p. 413-420, 2007.

MOREIRA, C.A.; BRAGA, A.C.O. Aplicação de métodos geofísicos no monitoramento de área contaminada sob atenuação natural. Revista Engenharia Sanitária e Ambiental, v. 14. n. 2. p. 257-264, 2009a.

Caracterização geoelétrica de contaminantes provenientes da decomposição de resíduos sólidos domiciliares. Revista Ambiente e Água, v. 4. n. 2. p. 106-114, 2009b.

MOREIRA, C.A.; DOURADO J.C. Monitoramento da atenuação natural de pluma de contaminação pelo método de radar de epenetração no solo (GPR). Revista Brasileira de Geofísica, v. 25. n. 4. p. 389-398, 2007.

MOURA, H.P. Emprego da eletrorresistividade e da polarização induzida na caracterização geoelétrica de áreas de disposição de resíduos sólidos urbanos. Tese (Doutorado em Geociências e Meio Ambiente), Universidade Estadual Paulista "Júlio de Mesquita Filho", Rio Claro, SP, 2002.

MOURA, H. P.; MALAGUTTI FILHO, W. Métodos de eletrorresistividade e de polarização induzida aplicados na área de disposição de resíduos urbanos: Aterro Controlado de Rio Claro-SP. Revista Geociências, São Paulo, v. 22, n. Especial, p. 129-139, 2003.

Métodos da eletrorresistividade e da polarização induzida aplicados no estudo do aterro controlado de Piracicaba-SP. Revista Geociências, São Paulo, v. 26, n. 1, p. 35-43, 2007.

SHIRAIWA, S. et al. Estudos geofísicos integrados no lixão de Cuiabá, MT, Brasil: resultados preliminares. Revista Brasileira de Geofísica, v. 20, n. 3, p. 181-186, 2002.

SILVA, J.E. et al. Aplicação de ensaios elétricos e eletromagnéticos em problema de poluição ambiental. Revista Brasileira de Geofísica, v. 20, n. 3, p. 193-198, 2002.

TANDEL, Y.R. Contribuição ao estudo da poluição provocada no aqüifero freático e no solo pelo aterro controlado da cidade de Rio Claro, SP. Tese (Doutorado em Geologia), Universidade de São Paulo, São Paulo, SP, 1998.

ZAINE, J.E. Geologia da Formação Rio Claro na folha Rio Claro (SP). Dissertação (Mestrado em Geociências), Universidade Estadual Paulista "Júlio de Mesquita Filho", Rio Claro, SP, 1994.

ZONGE, K.; WYNN, J.; URQUHARTS, S. Resistivity, Induced Polarization, and Complex Resistivity. In: BUTLER, D. K. (Ed.). Near Surface Geophysics. Tulsa, OK: SEG, 2005. p. 265-300. 